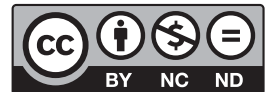

Estudos Teológicos foi licenciado com uma Licença Creative Commons Atribuição - NãoComercial - SemDerivados 3.0 Não Adaptada

http://dx.doi.org/10.22351/et.v60i3.4043

\title{
ACOlHer o OUTRo de Nós Mesmos: MIGRAÇÃO, CUIDADO E HOSPITALIDADE ${ }^{1}$ \\ Welcoming the other of ourselves: migration, care and hospitality
}

Abdruschin Schaeffer Rocha ${ }^{2}$
David Mesquiati de Oliveira ${ }^{3}$

Resumo: O tema da migração surge no texto a partir da noção de cuidado como modo-de-ser que se expressa em uma hospitalidade profunda, capaz de relativizar as diferenças para se construir partilha de vida. A reflexão caminha sobre a necessidade de se viver a hospitalidade profunda, que é capaz de acolher o outro para além das diferenças, em um desafio constante não só de aceitar o outro, mas acolher as próprias estranhezas internas de cada um.

Palavras-chave: Teologia das Migrações. Hospitalidade. Cuidado.

Abstract: The theme of migration arises in the text from the notion of care as a way of being that is expressed in a deep hospitality. This attitude would be able to put differences in perspective to build life sharing. To live in deep hospitality is to be able to welcome the other beyond differences, in a constant challenge not only to accept the other but also to accept the inner strangeness of each other.

Keywords: Theology of Migrations. Hospitality. Care.

\section{Introdução}

A partir de uma visão ampliada de hospitalidade e cuidado, propomos refletir sobre o gesto hospitaleiro como uma forma de cuidado no seguimento de Jesus. Cuidado esse que se estende para além do cristão, atingindo a cidadania laica. Como bem apontou João Manuel Duque, a categoria da hospitalidade pode representar o lócus de uma ética anterior ao Estado, superando, portanto, as distinções entre nacional e estrangeiro. ${ }^{4} \mathrm{O}$ texto é uma contribuição à teologia das migrações. Questões como $o$ que vem antes do cuidado ao estrangeiro e o que significa o acolhimento do outro nortearam essa pesquisa.

1 O artigo foi recebido em 27 de junho de 2020 e aprovado em 20 de novembro de 2020 com base nas avaliações dos pareceristas ad hoc.

2 Doutor. Faculdade Unida de Vitória. E-mail: abdo@fuv.edu.br

3 Doutor. Faculdade Unida de Vitória. E-mail: david@fuv.edu.br

4 DUQUE, João Manuel. Hospitalidade e violência. Sobre um possível fundamento religioso anterior ao estado laico. Franciscanum, Bogotá, v. 59, n. 167, p. 197-213, jan./jul. 2017. p. 198. 
O artigo está dividido em quatro seções. Na primeira, introduz o tema da mobilidade humana e apresenta algumas correntes teóricas que buscaram sistematizar o assunto. Na segunda seção, concentra-se em refletir sobre o que viria antes do cuidado ao outro, discutindo a noção de cuidado como modo-de-ser. Na terceira, aprofunda a noção de hospitalidade e acolhida do outro. Na quarta seção, finaliza com uma aplicação a partir da parábola do bom samaritano.

\section{Mobilidade humana, correntes teóricas e teologia}

A mobilidade humana ao longo da história tem produzido distintas experiências de (des)territorialização, promovendo toda sorte de encontros com o outro, quase sempre permeados de incerteza e de desconfiança mútua, mas também de gratuidade da acolhida na forma de hospitalidade. Neste artigo, queremos pensar não os fluxos migratórios em si, mas o migrante (e o estrangeiro) enquanto aquele que se movimenta e se coloca em flagrante situação de vulnerabilidade, diante da qual os nacionais, tanto a comunidade como os diferentes agentes da interação social, são instados a responder minimamente a partir dos Direitos Humanos.

O migrante é a pessoa que tem a intenção de mudar de lugar para instalar-se efetivamente em um novo local, de forma temporal ou permanente, e vai além do status jurídico de estrangeiro, que é aquele que não é considerado nacional de um determinado país. ${ }^{5}$ Mas, como afirma Farena, "migrante e estrangeiro se confundem como vítima. Ou seja, a discriminação e as violações de direitos são quase sempre praticadas contra os imigrantes, porque são estrangeiros" ". E amplia: "além disso geralmente são pessoas com características étnicas e raciais diferentes dos nacionais"7.

Os deslocamentos podem ser forçados ou mesmo voluntários, sendo que os compulsórios podem ser por razões de guerra, problemas ambientais, epidemias, perseguições, escravidão, entre outras, respondendo pelos movimentos mais significativos na história. ${ }^{8}$ Migração é um movimento ambíguo, pois produz aproximação entre pessoas e culturas e ao mesmo tempo permite a negação do lugar do outro.

Os estudos sistemáticos sobre a migração começaram no final do século XIX, tendo como marco a obra de Ernst Georg Ravenstein. ${ }^{9}$ Joaquín Arango avalia os estudos de Ravenstein cem anos depois de sua publicação e ratifica seu valor básico e

5 GASPARET, Murialdo. Mobilidade e evangelização: $\mathrm{O}$ atendimento pastoral de brasileiros católicos no exterior: o exemplo de Boston - América do Norte. 2018. Tese (Doutorado) - Departamento de Teologia, Pontifícia Universidade Católica do Rio de Janeiro, Rio de Janeiro, 2018. p. 21.

6 FARENA, M. N. F. C. Direitos humanos dos migrantes: ordem jurídica internacional e brasileira. Curitiba: Juruá, 2012. p. 31.

7 FARENA, 2012, p. 31.

8 MÁRMORA, Lelio. Derechos Humanos y Políticas Migratorias. In: IRIGOIN, Jeanet (Ed.). Nuevas Dimensiones en la Protección del Individuo. Santiago de Chile: Instituto de Estudios Internacionales de la Universidad de Chile, 1991. p. 72.

9 RAVENSTEIN, Ernst G. The laws of migration. Journal of the Statistical Society on London, v. 48, n. 2, p. 167-227, 1885; RAVENSTEIN, Ernst G. The laws of migration. Journal of the Royal Statistical Society, v. 52, n. 2, p. 241-301, 1889. 
teórico, mas encontra-os já inadequados para a realidade migratória atual, que seria mais complexa que os fluxos anteriores, seja pelo contingente populacional ou pelos efeitos da globalização neoliberal. ${ }^{10}$ Os estudos de Massey buscam explicar a migração a partir de critérios microeconômicos (decisão individual e utilitarista sobre custos e benefícios). ${ }^{11}$ Outros, como Castles \& Miller, admitem que as questões econômicas não são de todo conhecidas pelos migrantes e buscam a explicação a partir de questões macro (histórico-conjuntural). ${ }^{12}$ Charles Wood já discordava das decisões individuais e defendia que a decisão de migrar dá-se no núcleo familiar, ensejando modelos chamados de decisão intradomiciliares. ${ }^{13}$ Além da questão do trabalho e da economia, os modelos clássicos e neoclássicos sobre migração incorporaram os temas da diversidade cultural, do gênero e da religião.

É a partir dessa diversificação de fatores e da problematização das abordagens que é possível falar hoje de uma teologia das migrações. Essa teologia toma a compreensão da migração como um lugar teológico, a partir de duas constatações: a fé cristã traz em seu âmago movimentos importantíssimos de Deus em relação a ele mesmo (Trindade) e em relação à história; os fluxos experimentados pelos deslocamentos de indivíduos e de comunidades e as demandas de cuidado que suscitam. ${ }^{14}$ Carmen Lussi e Gioacchino Campese apresentam um panorama das teologias das migrações em perspectiva histórica, auxiliando na sistematização dessa corrente. ${ }^{15}$

Recentemente, o papa Francisco tem se pronunciado em relação ao tema da migração. Reiteradas vezes o pontífice defendeu o Pacto Global para uma Migração Segura, documento que no final de 2018 foi endossado pela Assembleia Geral das Nações Unidas, com 164 Estados-membros signatários. ${ }^{16}$ Além disso, o pontífice vem tratando o tema pastoralmente. Em uma homilia no dia 06 de julho de 2018, na Ilha de Lampedusa, Itália, o papa Francisco trouxe à memória os mortos e os sobreviventes dos desembarques de imigrantes nas diferentes costas marítimas do mundo. Manoel Tavares registra: "aos socorristas o Papa expressou sua gratidão por encarnarem a

10 ARANGO, Joaquín. Las leyes de las migraciones de E. G. Ravenstein, cien años después. Revista Española de Investigaciones Sociológicas, v. 32, p. 7-26, 1985.

11 MASSEY, D. S. et al. Worlds in motion. Understanding international migration at the end of the millennium. Oxford; New York: Oxford University Press, 2005.

12 CASTLES, S.; MILLER, M. J. The age of Migration. International population movements in the modern world. New York; London: The Guilford Press, 2009.

13 WOOD, Charles H. Equilibrium and historical-structural perspectives on migration. International Migration Review, 16, n. 2, p. 298-318, 1982.

14 BAGGIO, Fabbio; BRAZAL, Agnes (Eds.). Faith on the move: Toward a Theology of Migration in Asia. Manila: Ateneo de Manila University Press, 2008.

${ }^{15}$ LUSSI, Carmen. Mobilidade humana como lugar teológico. Elementos de teologia das migrações. Concilium, v. 328, n. 5, 2008; CAMPESE, Gioacchino. Non sei più straniera nèospite. La teologia delle migrazioni nel XXI secolo. In: MANENTI, R. (Dir.). Studi Emigrazione: International Journal of Migration Studies. Rivista trimestrale di ricerca, studio e dibattito sul fenomeno migratório, v. 47, n. 178, p. 317-345, 2010.

16 ONU. Nações Unidas Brasil. Assembleia Geral da ONU adota oficialmente Pacto Global para a Migração. 20 dez. 2018. Disponível em: <https://nacoesunidas.org/assembleia-geral-da-onu-adota-oficialmentepacto-global-para-a-migracao/>. Acesso em: 15 jan. 2020. 
parábola do Bom Samaritano, salvando vidas"17. Em uma mensagem para o evento XXVIII Dia Mundial do Enfermo, o papa voltou a citar a parábola do bom samaritano como referencial para ajudar os que sofrem. De acordo com Manoela Castro, o papa afirmou: "A Igreja lembra que o caminho mais crível de evangelização são os gestos de dom gratuito como os do Bom Samaritano"18. Em 27 de janeiro de 2019, na visita de Francisco à Casa Lar do Bom Samaritano no Panamá, por ocasião da Jornada Mundial da Juventude, o papa voltou a fazer menção expressa da parábola:

O próximo é uma pessoa, um rosto que encontramos na estrada, e pelo qual nos deixamos mover, saímos de onde estamos: mova-se dos seus esquemas e prioridades e avance profundamente no que essa pessoa vive, para dar-lhe lugar e espaço em sua caminhada. É assim que o Bom Samaritano, diante do homem que estava meio morto ao lado da estrada, não só por bandidos, mas também pela indiferença de um sacerdote e um levita que não se atreveram a ajudar. [sic] Porque, vocês sabem, a indiferença também mata, dói. E pode matar a uns por algumas moedas miseráveis, a outros por medo. Medo de contaminação, ou por desprezo ou repugnância social ${ }^{19}$.

A seguir aprofundaremos os conceitos de cuidado, hospitalidade e "próximo", para, ao final, refletir sobre como a parábola do bom samaritano ${ }^{20}$ pode contribuir para uma teologia das migrações.

\section{Migração e cuidado}

A cena do acolhimento hospitaleiro implica pessoas em deslocamento e uma terra acolhedora, composta por seres humanos que se importam com a necessidade do peregrino e que criam estruturas de cuidado. E esses personagens não são estanques, mas dinâmicos. Isso porque todos partilhamos da condição de peregrinos e do estranhamento em relação a determinadas questões que nos compõem. Nossas identidades estão dadas em relação ao outro, limites que não podem ser traçados com tanta

17 TAVARES, Manoel. Papa sobre migração: a solidariedade é a única resposta sensata. Vatican News. 06 jul. 2018. Disponível em: <https:/www.vaticannews.va/pt/papa/news/2018-07/papa-francisco-missamigrantes.html [n.p.]>.

18 CASTRO, Manoela. Papa: seguir o exemplo do Bom Samaritano para socorrer os doentes. Vatican News. 08 jan. 2019. Disponível em: <https://www.vaticannews.va/pt/papa/news/2019-01/papa-franciscomensagem-dia-mundial-enfermo.html. [n.p.]>.

19 FRANCISCO apud GIANESINI, Luciana. Lições da JMJ: 12 frases do Papa Francisco. A12. Jovens de Maria. 29 jan. 2019. Disponível em: <https://www.a12.com/jovensdemaria/noticias/licoes-da-jmj-12frases-do-papa-francisco. [n.p.]>.

20 A parábola está em Lucas 10.25-37, em que uma pessoa à beira do caminho é negligenciada pelo sacerdote e pelo levita, mas é cuidada por um samaritano, alguém que o auditório original da parábola segregava. O bom samaritano é apresentado como exemplo do agir misericordioso. Usamos como base BAILEY, Kenneth. A poesia e o camponês: uma análise literária-cultural das parábolas em Lucas. São Paulo: Vida Nova, 1985; JEREMIAS, Joachim. As parábolas de Jesus. 5. ed. São Paulo: Paulus, 1986 e GOURGUES, Michel. As parábolas de Lucas: do contexto às ressonâncias. São Paulo: Loyola, 2005. 
clareza quanto se gostaria de estabelecer. ${ }^{21}$ Essa dinâmica do estranho que também somos em relação ao outro e até em relação a nós mesmos, bem como os diferentes processos de territorialização e desterritorialização que passamos ao longo da vida, converte-nos em permanentes peregrinos. Que cuidado podemos esperar e generosamente partilhar? E antes disso, que força poderá nos empurrar para o acolhimento de forma adequada?

"Quem é o meu próximo?" Essa é a questão que suscita a parábola de Lucas 10.25-37. Para o doutor da lei, que na narrativa é quem inicia a conversa, antes de amar o próximo é preciso defini-lo. Ou seja, não se pode amar alguém como próximo - qualificação dada pelo Decálogo e confirmada por Jesus - sem saber quem é esse próximo. O doutor da lei quer saber se a compreensão de Jesus daquele a quem se deve amar se encontra nos limites de sua conceituação. Ele sugere que amar a Deus, na intensidade descrita, não era um problema. Sua crise, na verdade, era com o outro e, nesse sentido, não destoa muito do desafio contemporâneo da convivência, algo cada vez mais desafiador num mundo globalizado.

É possível verificar na história essa recorrente necessidade de se classificar as pessoas antes de amá-las ou mesmo de odiá-las. A própria violência, que expressa em termos gerais o descuido e descaso para com o humano, muitas vezes passa pelo estabelecimento de limites conceituais. Como exemplo pode-se citar os movimentos de não violência, que tiveram lugar a partir do século XIX, nos Estados Unidos. Na opinião de Domenico Losurdo, tais movimentos sucumbiram a algum tipo de violência, muitas vezes legitimado pelo estabelecimento de limites conceituais que procuraram estabelecer o que constitui o ser humano e o que constitui a própria violência. ${ }^{22}$

Losurdo narra a evolução dramática da compreensão de não violência de alguns protagonistas de movimentos abolicionistas. É o caso de Charles Stearns, um dos mais rigorosos personagens do movimento não violento e abolicionista. Embora inicialmente contrário a qualquer tipo de violência, mesmo aquela que resultasse da defesa pelos direitos dos escravos, Stearns paulatinamente se vê confrontado em sua posição quando é exposto aos assassinatos a sangue frio dos abolicionistas, levados a efeito no Kansas pelos escravagistas. É nesse contexto que Stearns abandona sua antiga posição ao afirmar que "a não resistência proíbe somente de apagar a vida de um ser humano [...] Mas esses homens não são homens, e sim animais selvagens" ${ }^{\prime 2}$. Semelhantemente, William Garrison, "o líder mais prestigioso do movimento abolicionista e não violento" "24, de um forte crítico das ações violentas dos abolicionistas - inclusive crítico do "segundo Stearns" e de todos os que foram favoráveis à resistência armada contra quadrilhas provenientes do Sul -, transforma-se não só num defensor

${ }^{21}$ Por vezes a negação do outro, que se expressa na forma de preconceito ou mesmo de violência explícita, deriva dessa necessidade de delimitarmos o cuidado ou a quem se deve amar, como consequência de uma necessidade de afirmação da identidade. É o lado ruim dessa afirmação. Ou seja, nossa identidade exclui a participação do outro em sua constituição e o demoniza.

${ }^{22}$ LOSURDO, Domenico. A não violência: uma história fora do mito. Rio de Janeiro: Revan, 2012.

23 ZIEGLER apud LOSURDO, 2012, p. 26.

${ }^{24}$ LOSURDO, 2012, p. 28. 
da resistência armada, mas também em alguém que se empenha vigorosamente numa consagração teológica da própria violência. ${ }^{25}$ Esses e tantos outros ativistas foram forçados a redefinir o conceito de humano ou mesmo o de violência em função de suas experiências com o lado mais sombrio do ser humano. Percebe-se aqui que há uma clara materialização histórica da mesma problemática que se verifica no horizonte da parábola. A legitimação teológica da violência, ativa ou passiva, é uma força que sempre se presta a justificá-la, aplacando as consciências e emprestando-lhe autoridade.

Essa delimitação do que seja o próximo ou mesmo do que seja o ser humano acaba por se revelar de suma importância na parábola, na medida em que se coloca como o ponto de partida para a tensão que se instalará na narrativa. A pergunta inicial revela o preconceito de quem pergunta, e é por isso que não deve ser respondida em seus próprios termos. Jesus não se presta apenas a responder perguntas, como se estivesse à disposição de seus inquiridores. Afinal, às vezes não se trata apenas de responder a uma pergunta, trata-se de mostrar o seu equívoco. Perguntas erradas, sobretudo quando são respondidas em seus próprios termos, podem conduzir a caminhos equivocados. Nas parábolas, isso ocorre com frequência. E é por isso que Jesus inverte a pergunta: não se trata mais de saber "quem é o meu próximo", como sugere o doutor da lei; trata-se muito mais de saber "de quem eu devo ser próximo". Jesus sugere que precisamos nos tornar o próximo de todo "sujeito histórico" que precisa de nós: o necessitado, o despossuído, o abusado, o explorado etc.

Há algo de fundamental importância que inicialmente deve ser destacado na parábola: qualificar alguém como "próximo" depende de que antes seja visto. Ou seja, pessoas invisíveis estão fora do raio de ação do cuidado, seja ele expresso em contexto religioso ou não. Essa invisibilidade pode ser social - a ideia de que determinada posição que se ocupa na sociedade torna as pessoas invisíveis $-{ }^{26}$ ou mesmo resultante de limites conceituais muito restritos do que efetivamente se constitua o ser humano, como vimos em Stearns e Garrison. Qualificar o outro como próximo implica, portanto, a exigência de que antes seja visto. Na narrativa, Jesus deixa claro o que significa ver o outro. Embora aparentemente todos tenham visto o homem ferido, na verdade, apenas o que se compadeceu e se mobilizou de fato o viu.

Há uma dimensão do cuidado que pode nos ajudar quando diante de controvérsias étnico-religiosas que surgem como impedimento ao acolhimento do outro, tais como aquelas que frequentemente estão presentes na discussão sobre migração. Qualquer disposição de hospitalidade e aceitação que se pretenda diante do outro passa, inevitavelmente, por uma compreensão de cuidado que deve retroceder aos níveis mais básicos e profundos de nossa humanidade, para aquém de toda identificação de raça ou mesmo de religião. Obviamente, estão sub iudice aqui as manifestações de cuidado que, à semelhança do padrão criticado por Jesus na parábola de Lucas 10.25-37, delimitam-se por critérios que vão muito além da simples condição de ser

${ }^{25}$ A respeito de Garrison, afirma Losurdo: "A não resistência deu lugar à violência, e a uma violência ulteriormente alimentada pelo furor teológico" (LOSURDO, 2012, p. 31).

${ }^{26}$ Quanto a esse tipo de invisibilidade, ver COSTA, F. B. da. Homens invisiveis: relatos de uma humilhação social. São Paulo: Globo, 2004. 
humano. ${ }^{27}$ Uma possibilidade que nos permite superar os modelos de cuidado que se definem exclusivamente pelos laços étnicos e religiosos é entender o cuidado como modo-de-ser, no sentido heideggeriano. Em sua obra Ser e Tempo, Heidegger expõe o seu conceito de cuidado considerado a partir de contornos ontológicos. ${ }^{28}$ Sorge (cuidado, cura) designa um modo-de-ser próprio do ser humano que não se confunde com ações de cuidar, nem mesmo atitudes de cuidado. Para ele, o ser humano (Dasein) é visto como alguém lançado no mundo, que se constitui a partir das próprias relações com este mundo e também a partir das relações com os outros seres humanos. Heidegger propõe, portanto, o cuidado como um modo-de-ser do ser humano. Nas palavras de Reale e Antiseri:

[...] assim como o ser-no-mundo do homem se expressa pelo cuidar das coisas, do mesmo modo o seu ser-com-os-outros se expressa pelo cuidar dos outros, coisa que constitui a estrutura basilar de toda possível relação entre os homens. E o cuidar dos outros pode tomar duas direções: na primeira, procura-se subtrair os outros de seus cuidados; na segunda, procura-se ajudá-los a conquistar a liberdade de assumir seus próprios cuidados. No primeiro caso, temos um simples "estar junto" e estamos diante da forma inautêntica de coexistência; no segundo caso, ao contrário, temos autêntico "coexistir"

Em Heidegger, tanto o ser-no-mundo quanto o ser-com-os-outros devem ser compreendidos como lugares constitutivos do humano, possíveis mediante uma força fundamental: o cuidado. Na qualidade de "totalidade originária", o cuidado pode ser visto como o modo mais completo a partir do qual se mostra o ser do ser humano. Em seu sentido existencial (como um a priori), embora também seja encontrado em ações ou atitudes, o cuidado não se reduz a elas, pois as precede. É nesse sentido que para Heidegger, “'teoria' e 'prática' são possibilidades ontológicas de um ente cujo ser deve determinar-se como cura". ${ }^{30}$

O conceito de cuidado como modo-de-ser do ser humano nos proporciona compreendê-lo como uma instância que não se deixa delimitar por sua aplicabilidade. Ou seja, tanto o cuidado pastoral como o cuidado de vítimas da violência doméstica ou mesmo o cuidado de refugiados e estrangeiros, na medida em que nos revelam o espectro de possibilidades de aplicação a partir dos vários grupos humanos vulnerabilizados, falam apenas do raio de ação do cuidado, mas não de sua delimitação. Nesse sentido, o cuidado de pessoas que fazem parte do meu contexto étnico ou de

${ }^{27}$ É claro que não se pode falar de humano sem suas mediações culturais e religiosas, mas é preciso criticar aquelas que se mostram desumanizantes.

${ }^{28}$ HEIDEGGER, M. Ser e tempo. 2. ed. Petrópolis: Vozes; Bragança Paulista: Universitária São Francisco, 2007.

${ }^{29}$ REALE, G.; ANTISERI, D. História da filosofia: do romantismo até nossos dias. 6. ed. São Paulo: Paulus, 2003. v. 3, p. 585.

${ }^{30}$ HEIDEGGER, 2007, p. 261. Sobre o conceito de cuidado em Heidegger, ver ROCHA, Abdruschin Schaeffer. Revelação e vulnerabilidade: caminhos para uma hermenêutica da revelação a partir da presençaausência. 2015. Tese (Doutorado) - Departamento de Teologia, Pontifícia Universidade Católica do Rio de Janeiro, Rio de Janeiro, 2015. p. 217-220. 
minha religião não define o cuidado enquanto tal, apenas informa o contexto de sua materialização. Embora o ser humano se construa no mundo, é preciso assumir (com o perdão dos neologismos) certa "desprofissionalização", "desetnocentrização" e "desreligiocentrização" do cuidado.

\section{O estrangeiro e os encontros}

Ao destacar as incoerências do individualismo particularista e intransigente dos homens e mulheres modernos, Julia Kristeva aponta o real desafio atual: "não mais a da acolhida do estrangeiro no interior de um sistema que o anula, mas a da coabitação desses estrangeiros que todos nós reconhecemos ser"31 . Assim, no caso da parábola do samaritano, não se trata de simples acolhida do ser humano que estava em necessidade, mas de reconhecer que todos nós necessitamos de algo nas diferentes fases da vida e partilhamos de diferentes graus de "estranheza". Não basta treinar para acolher, mas educar para ser acolhedor, para aprender a lidar de forma harmoniosa com a diferença, sejam as internas ou as do próprio convívio social. Em geral, os treinamentos nos ajudam no nível das ações, mas com pouca repercussão no nível mais profundo do ser.

O estrangeiro não é somente o outro, como se nós estivéssemos no lugar-padrão que julga a partir do próprio. As estranhezas não habitam somente o outro, mas nos constituem identitariamente:

Estranhamente, o estrangeiro habita em nós: ele é a face oculta da nossa identidade, o espaço que arruína a nossa morada, o tempo em que se afundam o entendimento e a simpatia. Por reconhecê-lo em nós, poupamo-nos de ter que detestá-lo em si mesmo. Sintoma que torna o "nós" precisamente problemático, talvez impossível. O estrangeiro começa quando surge a consciência de minha diferença e termina quando nos reconhecemos todos estrangeiros, rebeldes aos vínculos e às comunidades. ${ }^{32}$

No caso da teologia, o cânon judaico-cristão pode oferecer subsídios para esse processo de formação para uma hospitalidade profunda. No entanto, deve-se ter claro o desafio para se sustentar uma teologia da hospitalidade a partir do texto canônico. Isso porque, e a título de exemplo, "não existe uma palavra para designar hospitalidade em hebreu bíblico. [...] O nome hebraico de hóspede ou viajante ('oreach) é muito pouco empregado na Bíblia e nunca no Pentateuco"33. Mais adiante Philippe Bornet afirma: "A ideia de hospitalidade, se não é inexistente no conjunto de textos bíblicos, é pelo menos pouco expressa, ao contrário da própria prática da hospitalidade de que

${ }^{31}$ KRISTEVA, Julia. Estrangeiros para nós mesmos. Rio de Janeiro: Rocco, 1994. p. 10.

32 KRISTEVA, 1994, p. 9.

${ }^{33}$ BORNET, Philippe. Judaísmo: entre normas religiosas e imperativos éticos. In: MONTANDON, Alain (Dir.). O livro da hospitalidade: acolhida do estrangeiro na história das culturas. São Paulo: Senac, 2011. p. 131-144, p. 132. 
temos numerosos relatos" ${ }^{34}$. Dessa forma, embora os laços entre hospitalidade e seu incontestável aspecto religioso possam ser flagrantes, a experiência do gesto hospitaleiro já se manifesta antes mesmo da religião, podendo revestir-se de aspecto sagrado no seio das religiões e chegar a constituir-se em dever religioso.

Faustino Teixeira afirma:

A hospitalidade envolve uma "dádiva de si", tendo uma grande familiaridade com a abertura ao outro e ao diálogo. No campo das religiões, a hospitalidade ganha um significado essencial. A acolhida ocorre no "solo sagrado" do outro, implicando um gesto magnífico, que coloca o sujeito diante de um risco preciso, que resolve toda a sua autocompreensão $0^{35}$.

No Antigo Testamento (AT) são considerados distintos tipos de estrangeiros, com sentidos nem sempre claros nas traduções. A expressão zar é mais ampla e designa qualquer pessoa que não pertença a um determinado grupo, como aparece em Exxodo 29.33; 1 Reis 3.18; Isaías 43.12. É uma espécie de forasteiro e pode vir a ser identificado até com um inimigo, como ocorre em Isaías 1.7; Jeremias 5.19; 51.51; Ezequiel 7.21, 28; Obadias $11 .{ }^{36}$ Essa variação de sentido denota a tensão que existe em relação ao estrangeiro, que se mostra como um potencial inimigo. Outros termos traduzidos por estrangeiro no AT são nekar e nokri (etimologicamente, "desconhecido), que aparecem, por exemplo, em Provérbios 20.16; 27.2,13. O estrangeiro seria aquela pessoa que possivelmente não tinha laços familiares com as famílias nacionais e precisava contar com a hospitalidade dos locais para sua acolhida social, uma vez que nessa condição não gozava de proteção social do Estado. Uma pessoa que pertencia a uma outra etnia, por razões culturais e religiosas, enfrentava muitas reservas por parte do povo hebreu/judeu, fruto de um exclusivismo monoteísta, que chegava a proibir casamentos interétnicos.

Outros termos como ger e tôšab faziam referência a um tipo específico de estrangeiro, aquele que poderia ser qualificado como emigrado ou refugiado, um tipo de colono ou mesmo dos peregrinos religiosos. Sua passagem pela região, temporária ou permanente, poderia indicar que sua vinda ao país fosse uma busca por proteção, gozando de direitos reconhecidos pelo Estado, como visto em Êxodo 22.21; 23.9; Levítico 19.33-34. Os israelitas não poderiam oprimi-los. Em Juízes 19.16 há um relato de um homem de Efraim que busca refúgio em Gabaá; os levitas, uma tribo inteira em Israel, gozavam de proteção social equivalente a um refugiado (Jz 17.7-9; 19.1; Dt 12.12; 14.29; 26.12) e tinham obrigações religiosas e cultuais (Êx 12.48s; Lv 16.29 ; 17.8-13; 18.26; 22.18; Nm 9.14; 15.14 - 16.29; 19.10; Dt 16.11,14). Há também trabalhadores e exilados do Reino do Norte (Êx 12.45; Lv 22.10; 25.40). Com o

34 BORNET, 2011, p. 132.

35 TEIXEIRA, Faustino. O sagrado dever da hospitalidade. In: GARCIA, Célio P. (Org.). Pentecostalismo e sociedade: impactos e/ou cumplicidades. São Paulo: Terceira Via, 2017. p. 101.

${ }^{36}$ LIMPISKI, Édouard. Estrangeiro. In: DICIONÁRIO Enciclopédico da Bíblia. São Paulo: Paulinas; Paulus; Loyola, 2013. p. 484. 
processo civilizatório, no fim do período bíblico, os termos ger e tôšab evoluíram para "prosélito" ou mesmo "temente a Deus", denotando que esse tipo de estrangeiro era mais assimilado pela cultura local que os demais. Em 2 Crônicas 2.17, no censo feito por Salomão, percebe-se a presença numerosa desses migrantes. Em Deuteronômio 10.19 ensina-se que eles deveriam ser amados pelo povo. ${ }^{37}$

Já no Novo Testamento (NT) o termo estrangeiro não é tão especializado como no AT, indicando geralmente alguém longe da sua pátria, estando subentendida a responsabilidade de cuidar do necessitado. No caso da parábola do bom samaritano, em Lucas 10.34, o necessitado foi levado a uma casa para acolhimento, uma hospedaria, do grego pandocheion, que significa "pleno acolhimento". Era diferente do grego $\mathrm{ka}$ taluma, "lugar em que se guardam as cavalgaduras e as bagagens", que era uma sala reservada aos hóspedes nas casas de curta duração, como em Lucas 2.7; 9.12; 19.7. Havia também a xenia, "alojamento", "quarto", um tipo de casa para receber estranhos e hóspedes de passagem, em troca de locação, como em Atos 28.23 e Filemom 22..$^{38}$

Na parábola, o samaritano conduz o necessitado não a um simples quarto para descansar, mas a uma casa de "pleno acolhimento". Ali receberia atenção médica, alimentação e hospedagem, ou seja, cuidado integral. Essa atenção e hospitalidade para com o estranho ajudavam a romper as barreiras étnicas, sociais, econômicas e religiosas. Há uma gratuidade ativa, um dom, que se ativa em resposta ao que se é: a ação de cuidar como resultado de um jeito de ser que se vê visceralmente vinculado ao outro.

Isso posto, fica evidente que a hospitalidade não é meramente espontânea, antes precisa ser trabalhada a partir de dentro, de uma ética existencial. Como afirma Alain Montandon, o gesto de hospitalidade pode transformar a hostilidade latente em acolhida cortês. ${ }^{39}$ É necessário materializar a hospitalidade por meio de processos políticos, realizando a utopia ${ }^{40}$ Contudo, uma hospitalidade regida por força de leis e acordos representa uma hospitalidade mais superficial, no sentido de já não ser mais incondicional, não estar em estado puro, como defendia Derrida: "abrir as portas a cada um e a cada uma, a todo e a qualquer outro, a todo recém-chegado, sem perguntas, mesmo sem identificação, de onde quer que ele viesse e fosse onde ele fosse" ${ }^{\text {"41 }}$. Esse acolhimento dialoga muito próximo com a receptividade das cidades-refúgio, contribuindo para se repensar a cidadania em seu sentido mais amplo. Uma hospitalidade que não flua da consciência de que mais do que agir cuidadosamente, somos o próprio Cuidado, sempre necessitará da lei como coerção para sua efetivação. Mas vimos na parábola que a hospitalidade sugerida por Jesus é de um tipo que excede a lei e todas as estruturas que institucionalizam o cuidado do outro.

No caso do samaritano, não se menciona nenhum diálogo entre quem ajuda e quem é amparado, apenas o acolhimento, sem perguntas e sem condições. No entanto,

\footnotetext{
${ }^{37}$ LIPINSKI, 2013, p. 484.

${ }^{38}$ RADERMAKERS, Jean. Hospedaria. In: DICIONÁRIO Enciclopédico da Bíblia. São Paulo: Paulinas; Paulus; Loyola, 2013. p. 647.

${ }^{39}$ MONTANDON (Dir.), 2011, p. 41.

${ }^{40}$ DUQUE, 2017, p. 211.

${ }^{41}$ DERRIDA, Jacques. Cosmopolitas de todos os países mais um esforço! Coimbra: Minerva, 2001. p. 47.
} 
não se pode deixar a hospitalidade reduzida a um impulso individual. Os processos políticos que geram reconhecimentos e direitos devem ser fortalecidos e ampliados. São essas materializações em legislação que culminam em processos civilizatórios que cooperaram para a segurança e o reconhecimento do estrangeiro enquanto tal. Ou seja, embora sejamos instados pela parábola a reconhecer que o cuidado está na base de nosso ser - prévio a toda ação, atitude ou coerção -, por outro lado, é preciso reconhecer a importância de leis que garantam a dignidade do outro, afinal, depois de algumas gerações, aquilo que fora imposto na origem pode passar a fazer parte de uma ética mais humanizadora que flua de sentimentos genuínos de cuidado do outro.

Henri Nouwen afirma que a hospitalidade "não é trazer homens e mulheres para o nosso círculo, mas oferecer uma liberdade sem as amarras de linhas divisórias". E prossegue: “o paradoxo da hospitalidade é que ela deseja criar o vazio, não um vazio temeroso, mas um vazio amistoso no qual os estranhos podem penetrar e descobrir a si mesmos livres como foram criados; livres para cantar suas canções, para falar suas línguas, para dançar suas danças" $"$.

Esse alargamento de fronteiras culminando na inclusão do outro, mesmo daquele que habita no meu eu, é uma utopia da hospitalidade profunda. Assim, a experiência da hospitalidade é resultante de uma ética paradoxal ou aporética, em que só é possível como impossível ${ }^{43}$, pois considera uma relação assimétrica entre o que necessita de ajuda e o que pode auxiliar, mas ainda tem potencial para gerar resultado harmonioso, a partir do gesto da hospitalidade, que não será tão generoso quanto poderia ser.

\section{A parábola como ponto de partida para o cuidado do estrangeiro}

Na parábola nada se diz sobre a etnia ou nacionalidade daquele que estava à beira do caminho em agonia. Bem poderia ser um membro da comunidade local em viagem, um peregrino religioso, um prosélito ou, de fato, um estrangeiro. Há um desnudamento proposital do ferido que o reduz a um mero ser humano em estado de necessidade. De fato, cuidar de alguém cuja identidade não está clara se constitui num enorme desafio, sobretudo em um mundo em que as identidades são bem delineadas e consolidadas. Há aqueles que estão mais próximos da fronteira e há aqueles que se encontram mais no interior do "sistema", longe da zona de tradução. Na medida em que se distanciam da fronteira e se deslocam para longe das margens, mais distantes também da zona onde se dá o diálogo e onde se poderia traduzir o outro em nós mesmos. ${ }^{44}$

Aquele que está diante de mim, a cada vez, em necessidade, torna-se o próximo por excelência, diria Jesus. Aqui também não se trata de "todo mundo", afinal, "todo mundo" não é ninguém. Essa "abstração ideal" tem perpassado a história, pelo menos desde Platão, gerando visões de mundo que tendem a perder o sujeito histórico

\footnotetext{
42 NOUWEN, Henri. Crescer: os três movimentos da vida espiritual. São Paulo: Paulinas, 2001. p. 69.

${ }^{43}$ Cf. DERRIDA, Jacques; DUFOURMATELLE, Anne. Da hospitalidade. Coimbra: Escuta, 2003.

${ }^{44}$ LÓTMAN, I. On the Semiosphere. Sign Systems Studies, v. 33, n. 1, 2005. p. 213.
} 
de vista. Mesmo na Modernidade, quando se celebrou com entusiasmo o protagonismo do sujeito, esse não passa de uma abstração, um exemplar intuível na multiplicidade (Idea). Na acepção de Jesus, o próximo que devemos ser só será relevante quando aquele que demanda o nosso cuidado for um indivíduo histórico, de carne e osso, que se encontra diante de mim. Não se trata, portanto, de um estrangeiro metafísico, conceitual, um exemplar abstrato, mas daquele que me interpela a cada vez, desde o seu próprio lugar. Para J. Jeremias, Jesus quer ensinar com a parábola que o próximo “com certeza deve ser para você primeiramente o seu concidadão, mas não só ele, como também todo aquele que precisar de sua ajuda" $" 4$.

Nesses termos, a hospitalidade se mostra como "algo precioso, com valor sagrado, que estabelece laços imarcescíveis entre aqueles que buscam crescer na experiência do Mistério e da busca do sentido"46. Júlio Zabatiero procura enxergar Jesus e sua vida como um exercício de hospitalidade: "Jesus foi entre nós o Deus hospitaleiro. Desceu à própria casa, que fora invadida e profanada, e mostrou as infindas possibilidades como um verdadeiro lar para todas as pessoas". E continua: "Foi entre nós o senhorio do salmo 23:5,6 que nos preparou uma festa em meio à raivosa reação dos adversários e abriu as portas da casa de Deus para todos, cheio de bondade e misericórdia, sem cobrar aluguel por tempo indeterminado"47. Esse olhar para o universo como animado pela dinâmica espiritual é compartilhado por Teixeira: "a hospitalidade ganha assim uma tessitura nova e exigente [...] que delineia os passos essenciais do significado mais profundo do habitar espiritualmente a Terra"48.

Apesar das diferenças entre o familiar e o estranho, que haja acolhimento. Esse gesto de acolher é uma forma do amor-caridade e do amor fraternal, o pronto reconhecimento do outro como irmão e irmã, ao qual se está vinculado de forma intensa. Foi nessa experiência fraterno-sororal que o Cristo se manifestou em carne humana, unindo homens e mulheres, negros e pardos, todas as etnias, em uma experiência teologal. Acolher o pobre e a viúva e, poderíamos expandir, acolher o estrangeiro, é acolher o próprio Cristo.

A hospitalidade levanta a questão do estrangeiro, a questão de um ser desconhecido, que vem de fora, um ser de passagem, não conforme aos hábitos do lugar, culturalmente deslocado, portanto, "estranho", exterior, insólito. Um ser que se distingue por seu não sedentarismo, sua língua, suas vestes, seus hábitos e costumes. Seu caráter não ordinário faz germinar uma suspeita: o estrangeiro bem poderia ser um deus - ele compartilha com os deuses a capacidade de ameaça e de dádiva. Assim, a hospitalidade aparece frequentemente sob a forma de uma teoxenia. ${ }^{49}$

45 JEREMIAS, 1986, p. 204.

46 TEIXEIRA, 2017, p. 104.

${ }^{47}$ ZABATIERO, Júlio P. T. Fundamentos da teologia prática. São Paulo: Mundo Cristão, 2005. p. 103.

48 TEIXEIRA, 2017, p. 105.

${ }^{49}$ MONTANDON (Dir.), 2011, p. 41. 
A teoxenia seria a expectativa da visita de um deus à casa dos mortais em que se veria testada a capacidade dos mesmos para a hospitalidade. Trata-se da vinda do extraordinário ao ordinário. É o ambiente da familiaridade que se abre (ou que é invadido) ao estranhamento. Em Mateus 25 estaria implícita uma teoxenia em relação ao encarcerado, faminto, sedento e aos despossuídos de forma geral? Podemos entender a parábola do samaritano como uma teoxenia? Jesus estava não só com o samaritano que se viu inclinado a acolher de forma profunda e compromissada aquele desconhecido, mas também estava com o que sofria à beira do caminho, mostrando que ao acolher o estrangeiro estava-se de fato acolhendo também o próprio Cristo, tendo a experiência de salvação como fruto de uma fé que brota nos gestos humanizadores e que geram vida, a vida de Deus. Jesus responde à pergunta do teólogo (v. 25) sobre a via para a vida eterna remetendo-o "ao agir como sendo a via para a vida". E com isso colocava em relevo: "todo conhecimento teológico de nada serve, se o amor para com Deus e para com o próximo não determinar a direção da vida" ${ }^{50}$. O sermão do pastor Ernesto Schlieper é categórico:

Cristo solidarizou-se conosco, inteiramente, tomando sobre si as nossas enfermidades, levando consigo para a cruz os nossos pecados. E é ele quem nos mostra o outro para que nele vejamos o nosso irmão. É Cristo quem nos espera por detrás do semblante do irmão, e isso quer dizer em primeiro lugar: do irmão que sofre, que é oprimido, que necessita de alguém que lhe seja irmão, e do qual Cristo disse: "O que fizestes a um destes meus irmãos mais pequeninos, a mim é o que o fizestes" (Mt 25:40). De tanta importância é para o Cristo o outro, o homem necessitado, que Cristo se identifica com ele: "O que a ele fizestes, a mim é que o fizestes". E com essa palavra nos diz o que lhe é importante e essencial: que haja misericórdia e solidariedade fraternal entre nós; que desapareça de nosso meio e em nossa atitude toda espécie de egoísmo; que vejamos no outro, seja ele quem for, o semblante de Cristo, com o seu olhar sobre nós, esperando pela nossa resposta ao seu amor ${ }^{51}$.

A hospitalidade como gesto sagrado e também de salvação revela a potência do transcendente sobre ações e atitudes que modelam a vida, evidenciando o pertencimento à divindade. Dessa forma, o gesto de hospitalidade em relação ao outro que se expressa no cuidado integral reacende os laços sociais e comunitários de uma humanidade fraterna e sororal e aguça a pertença divina ao participar da salvação de Jesus como atitude fundante de amor fraterno. ${ }^{52}$ Nessa dinâmica a vida de Deus é experimentada como salvação tanto sobre o que estende a mão para amparar quanto sobre o que é amparado. Unem-se vidas que apesar de seus estranhamentos podem se conectar profundamente; unem-se os planos humanos ao divino, ao se experimentar na imanência as pulsões da vida de Deus.

50 JEREMIAS, 1986, p. 202.

${ }^{51}$ SCHLIEPER, Ernesto. 1974. Apud ZWETSCH, Roberto. Missão como com-paixão. São Leopoldo: Sinodal, 2008. p. 387.

52 OLIVEIRA, David Mesquiati. Diálogo e missão nos Andes. Rio de Janeiro: PUC-Rio; São Paulo: Garimpo, 2017. p. 150-153. 


\section{Considerações finais}

Acolher o estrangeiro é, sob muitos aspectos, não apenas uma questão de convívio com o outro - uma exigência cada vez mais urgente diante de um mundo globalizado -, mas uma questão de convívio consigo mesmo. Na verdade, o outro a quem rejeitamos por sua condição inusitada, em geral, reside dentro de nós. Embora conduta reprovável, é comum projetarmos no outro aquilo que se encontra mal resolvido dentro de nós. As dificuldades de se aceitar o estranho derivam de nossas dificuldades e até incapacidades de acolher o estranho em nós. É necessário deixar falar o outro de nós mesmos, aquele que sempre rompe com o óbvio por sua condição deslocada, pois esse é também o princípio de toda a criatividade - condição também cada vez mais urgente diante da escassez de recursos e de espaços no planeta -, a possibilidade de novas leituras do mundo e daqueles que estão diante de nós.

Acolher o outro de nós mesmos é a possibilidade de irrompimento do absurdo que nos tira da inércia e do sono e nos põe em alerta. Acolher o outro de nós mesmos é visibilizar aqueles elementos em nós que não são mais perceptíveis e que, portanto, não mais reconhecemos, apesar de serem também um pouco de nós. Acolher o outro de nós mesmos é compreender a profundidade da própria identidade, que não se constrói apenas a partir do mesmo, mas, também, a partir do outro que nos interpela e nos fratura em nossa estabilidade. Acolher o outro de nós mesmos pode nos preparar melhor para compreender o caráter constitutivo do cuidado, a fim de que não dependamos mais da coercitividade da lei para o acolhimento do estrangeiro. Finalmente, acolher o outro de nós mesmos é não ter medo de se desnudar, ainda que essa condição rudimentar nos ameace pelo fato de aceitarmos constantemente os rótulos que a cultura nos impõe. Se é verdade que há um outro que mora no outro, como muito bem nos lembrou o Artur da Távola, também o é que há um outro que mora em nós. Somente uma hospitalidade profunda, que comece em nós mesmos e progrida em direção ao outro, é capaz de contribuir para a paz e convívio de todos os povos.

\section{Referências}

ARANGO, Joaquín. Las leyes de las migraciones de E. G. Ravenstein, cien años después. Revista Española de Investigaciones Sociológicas, v. 32, p. 7-26, 1985.

BAGGIO, Fabbio; BRAZAL, Agnes (Eds.). Faith on the move: Toward a Theology of Migration in Asia. Manila: Ateneo de Manila University Press, 2008.

BAILEY, Kenneth. A poesia e o camponês: uma análise literária-cultural das parábolas em Lucas. São Paulo: Vida Nova, 1985.

BORNET, Philippe. Judaísmo: entre normas religiosas e imperativos éticos. In: MONTANDON, Alain (Dir.). O livro da hospitalidade: acolhida do estrangeiro na história das culturas. São Paulo: Senac, 2011. p. 131-144.

CAMPESE, Gioacchino. Non sei più straniera nèospite. La teologia delle migrazioni nel XXI secolo. In: MANENTI, R. (Dir.). Studi Emigrazione: International Journal of Migration Studies. Rivista trimestrale di ricerca, studio e dibattito sul fenomeno migratório, v. 47, n. 178, p. 317-345, 2010. CASTLES, S.; MILLER, M. J. The age of Migration. International population movements in the modern world. New York; London: The Guilford Press, 2009. 
CASTRO, Manoela. Papa: seguir o exemplo do Bom Samaritano para socorrer os doentes. Vatican News. 08 jan. 2019. Disponível em: <https://www.vaticannews.va/pt/papa/news/2019-01/ papa-francisco-mensagem-dia-mundial-enfermo.html $>$.

COSTA, F. B. da. Homens invisíveis: relatos de uma humilhação social. São Paulo: Globo, 2004. DERRIDA, Jacques. Cosmopolitas de todos os países mais um esforço! Coimbra: Minerva, 2001. DERRIDA, Jacques; DUFOURMATELLE, Anne. Da hospitalidade. Coimbra: Escuta, 2003. DUQUE, João Manuel. Hospitalidade e violência. Sobre um possível fundamento religioso anterior ao estado laico. Franciscanum, Bogotá, v. 59, n. 167, p. 197-213, jan./jul. 2017.

FARENA, M. N. F. C. Direitos humanos dos migrantes: ordem jurídica internacional e brasileira. Curitiba: Juruá, 2012.

GASPARET, Murialdo. Mobilidade e evangelização: $\mathrm{O}$ atendimento pastoral de brasileiros católicos no exterior: o exemplo de Boston - América do Norte. 2018. Tese (Doutorado) - Departamento de Teologia, Pontifícia Universidade Católica do Rio de Janeiro, Rio de Janeiro, 2018. GIANESINI, Luciana. Lições da JMJ: 12 frases do Papa Francisco. A12. Jovens de Maria. 29 jan. 2019. Disponível em: <https://www.a12.com/jovensdemaria/noticias/licoes-da-jmj-12-frases-do-papa-francisco>.

GOURGUES, Michel. As parábolas de Lucas: do contexto às ressonâncias. São Paulo: Loyola, 2005. HEIDEGGER, M. Ser e tempo. 2. ed. Petrópolis: Vozes; Bragança Paulista: Universitária São Francisco, 2007.

JEREMIAS, Joachim. As parábolas de Jesus. 5. ed. São Paulo: Paulus, 1986.

KRISTEVA, Julia. Estrangeiros para nós mesmos. Rio de Janeiro: Rocco, 1994.

LIMPISKI, Édouard. Estrangeiro. In: DICIONÁRIO Enciclopédico da Bíblia. São Paulo: Paulinas; Paulus; Loyola, 2013. p. 484.

LOSURDO, Domenico. A não violência: uma história fora do mito. Rio de Janeiro: Revan, 2012. LÓTMAN, I. On the Semiosphere. Sign Systems Studies, v. 33, n. 1, 2005.

LUSSI, Carmen. Mobilidade humana como lugar teológico. Elementos de teologia das migrações. Concilium, v. 328, n. 5, 2008.

MÁRMORA, Lelio. Derechos Humanos y Políticas Migratorias. In: IRIGOIN, Jeanet (Ed.). Nuevas Dimensiones en la Protección del Individuo. Santiago de Chile: Instituto de Estudios Internacionales de la Universidad de Chile, 1991.

MASSEY, D. S. et al. Worlds in motion. Understanding international migration at the end of the millennium. Oxford; New York: Oxford University Press, 2005.

MONTANDON, Alain (Dir.). O livro da hospitalidade: acolhida do estrangeiro na história das culturas. São Paulo: Senac, 2011.

NOUWEN, Henri. Crescer: os três movimentos da vida espiritual. São Paulo: Paulinas, 2001, OLIVEIRA, David Mesquiati. Diálogo e missão nos Andes. Rio de Janeiro: PUC-Rio; São Paulo: Garimpo, 2017.

ONU. Nações Unidas Brasil. Assembleia Geral da ONU adota oficialmente Pacto Global para a Migração. 20 dez. 2018. Disponível em: $<$ https://nacoesunidas.org/assembleia-geral-da-onu-adota-oficialmente-pacto-global-para-a-migracao/>.

RADERMAKERS, Jean. Hospedaria. In: DICIONÁRIO Enciclopédico da Bíblia. São Paulo: Paulinas; Paulus; Loyola, 2013.

RAVENSTEIN, Ernst G. The laws of migration. Journal of the Royal Statistical Society, v. 52, n. 2, p. 241-301, 1889.

The laws of migration. Journal of the Statistical Society on London, v. 48, n. 2, p. $167-227,1885$.

REALE, G.; ANTISERI, D. História da filosofia: do romantismo até nossos dias. 6. ed. São Paulo: Paulus, 2003. v. 3. 
ROCHA, Abdruschin Schaeffer. Revelação e vulnerabilidade: caminhos para uma hermenêutica da revelação a partir da presença-ausência. 2015. Tese (Doutorado) - Departamento de Teologia, Pontifícia Universidade Católica do Rio de Janeiro, Rio de Janeiro, 2015.

TAVARES, Manoel. Papa sobre migração: a solidariedade é a única resposta sensata. Vatican News. 06 jul. 2018. Disponível em: <https://www.vaticannews.va/pt/papa/news/2018-07/papa-francisco-missa-migrantes.html>.

TEIXEIRA, Faustino. O sagrado dever da hospitalidade. In: GARCIA, Célio P. (Org.). Pentecostalismo e sociedade: impactos e/ou cumplicidades. São Paulo: Terceira Via, 2017. p. 101-105.

WOOD, Charles H. Equilibrium and historical-structural perspectives on migration. International Migration Review, 16, n. 2, p. 298-318, 1982.

ZWETSCH, Roberto. Missão como com-paixão. São Leopoldo: Sinodal, 2008. 